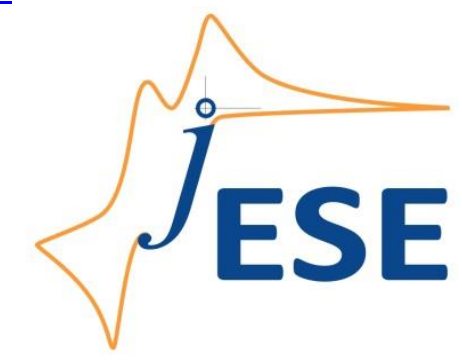

Open Access: ISSN 1847-9286

www.jESE-online.org

Original scientific paper

\title{
Modeling the effect of rib and channel dimensions on the performance of high temperature fuel cells-parallel configuration
}

\author{
Vikalp Jha and Balaji Krishnamurthy $\bowtie$ \\ Department of Chemical Engineering, BITS Pilani, Hyderabad 500078, India \\ Corresponding author: ${ }^{\bowtie}$ balaji.krishb1@gmail.com
}

Received: September 19, 2020; Revised: November 27, 2020; Accepted: November 27, 2020

\begin{abstract}
This work investigates the effect of rib width, channel width and channel depth on the performance of a high temperature proton exchange membrane (HT-PEM) fuel cell with parallel flow field configuration. Simulation results indicate that the rib width has the maximum impact on the performance of the fuel cell. The lower the rib width, the better is performance of HT-PEM fuel cell. Changing the channel width seems to have a moderate effect, while changing the channel depth seems to have very limited impact on the fuel cell performance. The effect of various rib width and channel dimensions on the pressure drop across the channel is also studied. The concentration profile of the oxygen across the cathode gas channel is modeled as a function of the channel width and depth. Modeling results are found to be in well agreement with experimental data.
\end{abstract}

\section{Keywords}

Fuel cell, modeling, rib width, channel width, pressure drop

\section{Introduction}

Improving the performance of a proton exchange membrane fuel cell (PEMFC) through modification of the flow field design has already been studied in literature for low temperature fuel cell systems. Yoon et al. [1] have studied the effect of rib width experimentally for $80 \mathrm{~cm}^{2}$ cell at different operating conditions. Shimpalee and Van Zee [2] have studied the impact of channel path length on $200 \mathrm{~cm}^{2}$ cells. The authors postulate that the effect of varying the flow channel path length on the reaction area can affect the performance of the cell. Shimpalee et al. [3] have also developed a model to study the impact of cross section dimension of channel and rib on the performance of low temperature PEMFCs. Hsieh and Chu [4] have experimentally investigated the effect of channel and rib widths with an aspect ratio 0.5 to 2 for the serpentine flow field PEMFC. Manso et al. [5] analyzed the effect of the channel cross section aspect ratio for serpentine flow fields. The authors postulate that channel cross section aspect ratio has a direct effect on the performance of PEMFCs. 
Wang et al. [6] have investigated the effect of channel to rib width ratio and geometric aspect ratio on the performance of PEMFC. The authors have shown that for some conditions, the interdigitated design is superior to the parallel design. In addition, Wang at al. ]7] have investigated the effect of sub rib convection on PEMFC with serpentine flow channels. They found that at low operating voltages, the reduced channel aspect ratio improves the cell performance. Chaudary et al. [8] have predicted that the effect of channel width is more pronounced than the land width. $\mathrm{Yu}$ et al. [9] have mentioned that the land width has little influence on the performance of PEMFC with interdigitated flow field. Goebel [10] has recommended the minimum land fraction of $50 \%$ for low contact resistance PEMFCs. Generally, there is a quite body of literature focusing on the effect of rib width and channel dimensions in low temperature fuel cells. On the other side, very little work has been done in the area of high temperature fuel cells, and just this will be the focus of the work presented in this paper.

\section{Modeling procedure}

\section{HT-PEMFC schematic}

Figure 1 shows the schematic of a parallel flow configuration in HT-PEM fuel cell and cross section of flow channels. The fuel cell has a polybenzamidazole membrane. Hydrogen and air are sent in the inlets of anode and cathode electrodes. The fuel cell is considered to operate at $130{ }^{\circ} \mathrm{C}$.

a

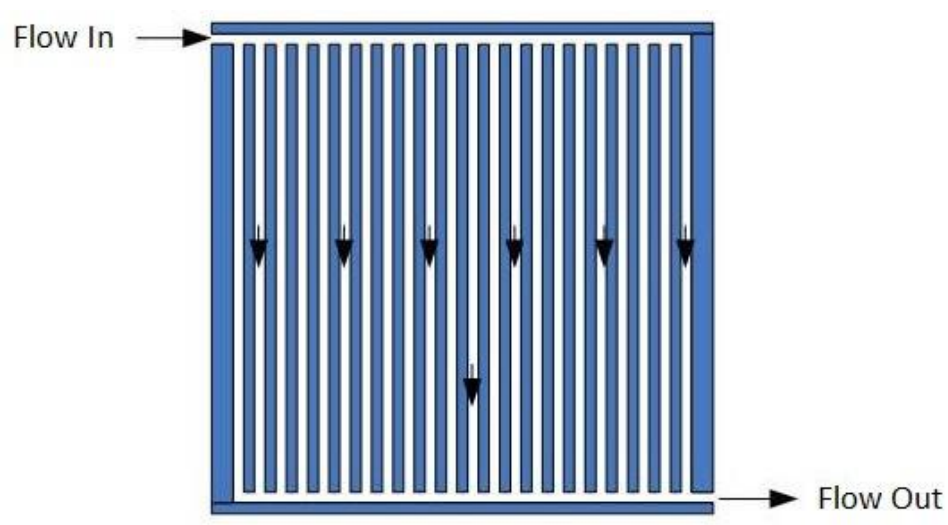

$\mathrm{b}$

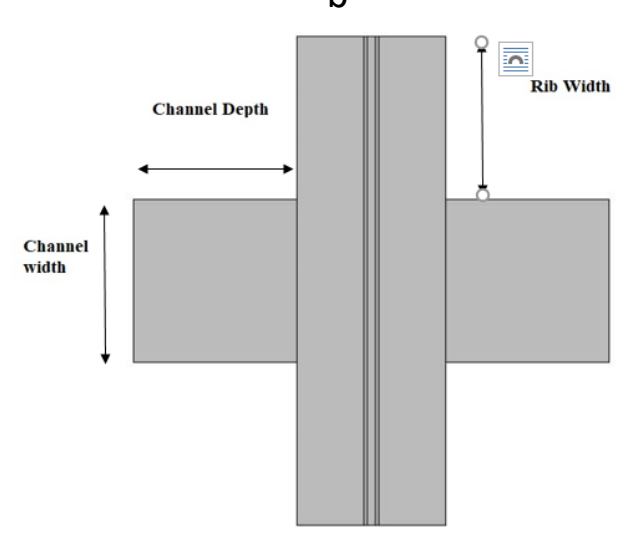

Figure 1. (a) Schematic of parallel flow configuration in HT-PEM fuel cell, (b) cross section of flow channels.

Model assumptions:

a) The model assumes steady state operating conditions.

b) The model assumes isothermal conditions. The temperature is assumed as $130{ }^{\circ} \mathrm{C}$.

c) The model assumes no phase change in a single-phase incompressible flow.

d) All gases and gas mixture behaviors are considered ideal.

e) Crossover of reactants and water vapor through the membrane are neglected.

f) The resistances due to gas diffusion layer (GDL) and catalyst layer are neglected.

g) Due to high temperature, water is considered as vapor.

Model equations:

Gas flow in flow channel path is governed by Navier-Stokes equations.

Mass and momentum conservation equations are given as follows:

$\nabla \rho u=0$ 


$$
\begin{aligned}
& \rho u \nabla u=-\nabla(-p l+\tau) \\
& \tau=\mu\left[\nabla u+(\nabla u)^{T}\right]-\frac{2}{3} \mu(\nabla u) l
\end{aligned}
$$

where $\rho$ is density, $u$ is velocity vector, $p$ is pressure, $\tau$ is viscous stress tensor, $l$ is the identify tensor and $\mu$ is dynamic viscosity.

Butler-Volmer equation which describes kinetics of electrochemical reactions at anode and cathode electrode interfaces is given by

$$
i=i_{\mathrm{o}}+\left[\exp \left(\frac{\alpha_{\mathrm{R}} F}{R T} \eta\right)-\right] \exp \left(\frac{-\alpha_{0} F}{R T} \eta\right)
$$

where $i$ and $i_{0}$ are current density and exchange current density, $\alpha_{\mathrm{R}}$ and $\alpha_{0}$ are anodic and cathodic transfer coefficients, $\eta$ is overpotential, $T$ denotes the operating temperature, while $F$ and $R$ is Faraday and gas constant, respectively.

For higher overpotential, Tafel equation can be derived from Butler-Volmer equation in the following form:

$$
\eta=A \ln \left(\frac{i}{i_{0}}\right)
$$

where $A$ denotes Tafel slope.

Ohm's law describes the charge transport in anode and cathode porous electrodes and electrolyte.

$$
\begin{aligned}
& \nabla i_{1}=Q_{1} \\
& i_{1}=-\sigma_{1} \nabla \varphi_{1} \\
& \nabla i_{s}=Q_{s} \\
& i_{s}=-\sigma_{s} \nabla \varphi_{s}
\end{aligned}
$$

where $i, Q, \sigma$, and $\phi$ denote current density, source mass term, conductivity, and potential for either electrolyte (subscript I) or solid electrode (subscript s).

Henry's law describes hydrogen and oxygen concentrations at the interface of electrode and membrane:

$$
\begin{gathered}
C_{\mathrm{H}_{2}}=\frac{x_{\mathrm{H}} P_{\mathrm{H}}}{K_{H}} \\
C_{\mathrm{O}_{2}}=\frac{x_{\mathrm{O}} P_{\mathrm{O}}}{K_{\mathrm{O}}}
\end{gathered}
$$

where $x_{H}$ and $x_{O}$ are hydrogen and oxygen mass fraction, while $K_{H}$ and $K_{\mathrm{O}}$ are Henry's constant. Brinkman equations (anode)

Brinkman equations are derived from Navier-Stokes equations for modelling of porous region Maxwell-Stefan equation describes transport of chemical species in ideal gas mixtures.

$$
\begin{aligned}
& \frac{\rho}{\varepsilon_{\mathrm{p}}}\left(u_{\mathrm{a}} \nabla\right) \frac{u_{\mathrm{a}}}{\varepsilon_{\mathrm{p}}}=\nabla\left[-p_{\mathrm{a}} l+\frac{\mu}{\varepsilon_{\mathrm{p}}}\left(\nabla u_{\mathrm{a}}+\left(\nabla u_{\mathrm{a}}\right)^{T}\right)-\frac{2}{3} \frac{\mu}{\varepsilon_{\mathrm{p}}}\left(\nabla u_{\mathrm{a}}\right) l\right]-\left(\mu \kappa^{-1}+\beta_{\mathrm{f}}\left|u_{\mathrm{a}}\right|+\frac{Q_{\mathrm{m}}}{\varepsilon_{\mathrm{p}}^{2}}\right) u_{\mathrm{a}}+F \\
& \nabla \rho u_{\mathrm{a}}=Q_{\mathrm{m}}
\end{aligned}
$$

Brinkman equations (cathode) 


$$
\begin{aligned}
& \frac{\rho}{\varepsilon_{\mathrm{p}}}\left(u_{\mathrm{c}} \nabla\right) \frac{u_{\mathrm{c}}}{\varepsilon_{\mathrm{p}}}=\nabla\left[-p_{\mathrm{c}} l+\frac{\mu}{\varepsilon_{\mathrm{p}}}\left(\nabla u_{\mathrm{c}}+\left(\nabla u_{\mathrm{c}}\right)^{T}\right)-\frac{2}{3} \frac{\mu}{\varepsilon_{\mathrm{p}}}\left(\nabla u_{\mathrm{c}}\right)\right]-\left(\mu \kappa^{-1}+\beta_{\mathrm{f}}\left|u_{\mathrm{c}}\right|+\frac{Q_{\mathrm{m}}}{\varepsilon_{\mathrm{p}}^{2}}\right) u_{\mathrm{c}}+F \\
& \nabla \rho u_{\mathrm{c}}=Q_{\mathrm{m}}
\end{aligned}
$$

where $\varepsilon_{\mathrm{p}}$ is GDL porosity, $p_{\mathrm{c}}$ and $p_{\mathrm{a}}$ are cathode pressure and anode pressure, $u_{\mathrm{c}}$ and $u_{\mathrm{a}}$ are cathode inlet velocity and anode inlet velocity, $\kappa$ denotes porous medium permeability, $\rho$ denotes density and $Q_{m}$ is mass source.

\section{Boundary conditions}

Applying the no slip boundary condition

$$
u_{\mathrm{c}}=u_{\mathrm{a}}=0
$$

Cathode inlet - laminar inflow

$$
L_{\text {entr }} \nabla_{t}\left[-p_{\mathrm{c}} I+\frac{\mu}{\varepsilon_{p}}\left(\nabla u_{\mathrm{c}}+\left(\nabla u_{\mathrm{c}}\right)^{T}-\frac{2}{3} \frac{\mu}{\varepsilon_{\mathrm{p}}}\left(\nabla u_{\mathrm{c}}\right) l\right)\right]=p_{\mathrm{entr}} n
$$

Anode inlet - laminar inflow

$$
L_{\text {entr }} \nabla_{t}\left[-p_{\mathrm{a}} I+\frac{\mu}{\varepsilon_{\mathrm{p}}}\left(\nabla u_{\mathrm{a}}+\left(\nabla u_{\mathrm{a}}\right)^{T}-\frac{2}{3} \frac{\mu}{\varepsilon_{\mathrm{p}}}\left(\nabla u_{\mathrm{a}}\right) I\right)\right]=p_{\text {entr }} n
$$

where $L_{\text {entr }}$ and $p_{\text {entr }}$ are entrance length and entrance pressure. The equations for species transport are given as follows:

$$
\begin{aligned}
& \nabla j_{\mathrm{i}}+\rho(u \nabla) \omega_{\mathrm{i}}=R_{\mathrm{i}} \\
& N_{\mathrm{i}}=j_{\mathrm{i}}+\rho u \omega_{\mathrm{i}}
\end{aligned}
$$

where $j_{i}$ is flux density, $u$ is velocity vector, $\rho$ is density and $\omega_{i}$ is mass fraction.

\section{Numerical simulations}

Three-dimensional computational domain of high temperature PEM fuel cell (HT-PEMFC) is shown in Figure 2. All geometrical parameters and properties are listed in Table 1.

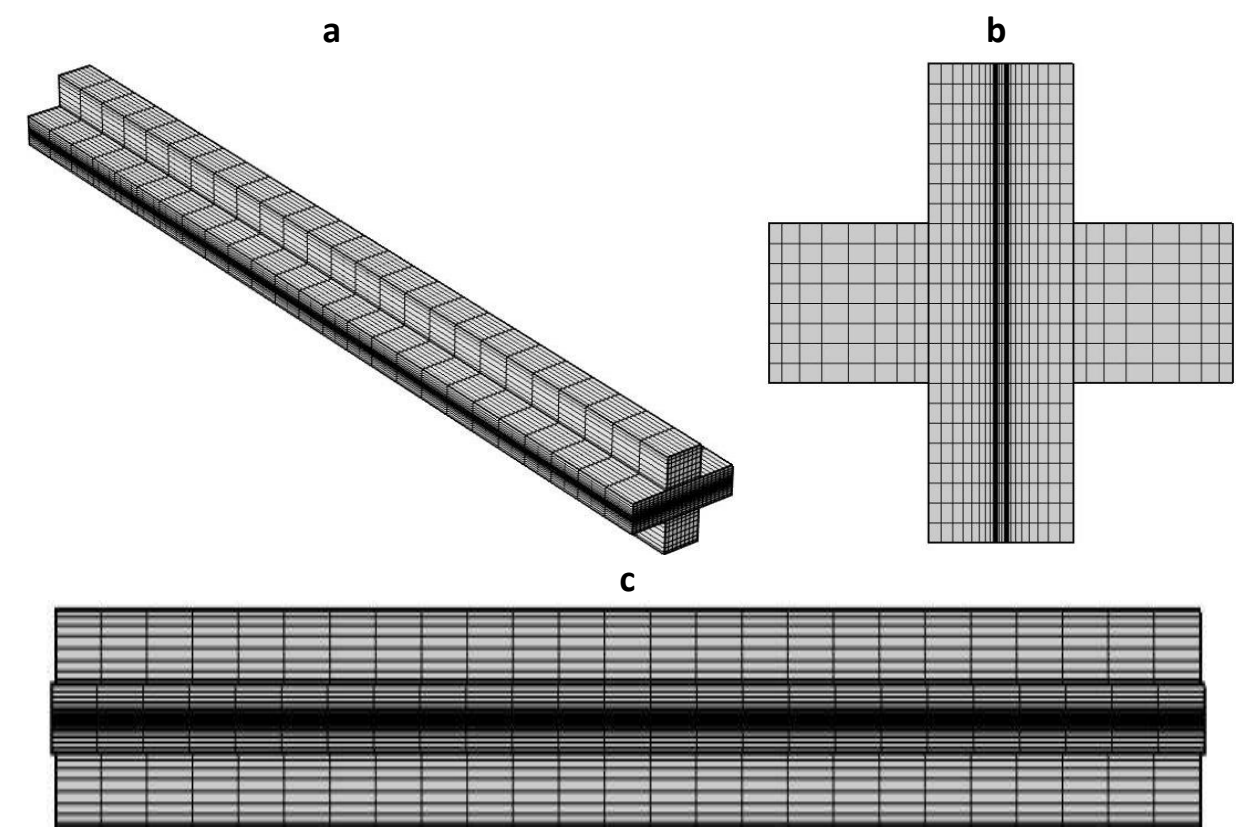

Figure 2. Mesh distribution in computational domain of HT-PEM fuel cell: (a) isometric view,

(b) cross section, (c) top view. 
In our optimization, various values $(0.5,1,1.5 \mathrm{~mm})$ of flow channel width, channel depth and rib width were considered for analysis. To study the effect of each of these three parameters individually, other two parameters were considered constant $(1 \mathrm{~mm})$. Rib width is considered equally on both sides of the channel. In our analysis, three different channel lengths $(19,22,25 \mathrm{~mm})$ were considered to observe flow properties across the flow channel. Structural hexahedral elements are used for meshing of computational flow domain. Our computational domain consists of 24200 hexahedral mesh elements, 8486 boundary elements and 1024 edge elements. Average skewness quality of our mesh elements is 1 . Mesh elements of our computational domain are adaptive with respect to various channel width, rib width and channel depth. A mathematical model is developed to analyze our computational domain in Comsol 5.3a on viable concerns of HT-PEM fuel cell, fluid dynamics, species transport and current distribution. Model equations with initial and final boundary conditions are solved using appropriate solvers.

\section{Results and discussion}

Wang et al. [11] has postulated that at low current densities where water accumulates in GDL (gas diffusion layer), the under-rib convection plays a more important role in water removal than the pressure drop. Water removal facilitates oxygen transportation and oxygen removal. At high current densities, when large amount of water accumulates in the channels, the pressure drop across the channels dominates water removal to facilitate oxygen transportation. This analogy can be extended to high temperature fuel cells for the removal of water vapor. Liu et al. [12] postulated that water is mostly accumulated along the rib edges and at the corners by the channel wall and GDL. The authors postulated that a smaller channel width and smaller rib width enables better hydration of the membrane and easier discharge of water, leading thus to better fuel cell performance. A larger channel dimension gives enhanced surface area for reaction. However, a larger channel/rib dimension while enhancing the electrical and heat conduction in the fuel cell also reduces the ohmic drop across the cell. Thus, the effects of rib and channel dimensions must be considered as a combination of these factors.

Figure 3 shows the simulated polarization curves describing the fuel cell performance as a function of different rib widths $(0.5,1,1.5,2 \mathrm{~mm})$. For these simulations, the channel width and channel depth are kept constant at $1 \mathrm{~mm}$. The graph shows that the fuel cell performance is the highest at the rib width of $0.5 \mathrm{~mm}$, and the lowest at the rib width of $2.0 \mathrm{~mm}$. The difference in the fuel cell performance for different rib widths is higher within the high current density zone, indicating mass transfer limitations and major role of water discharge.

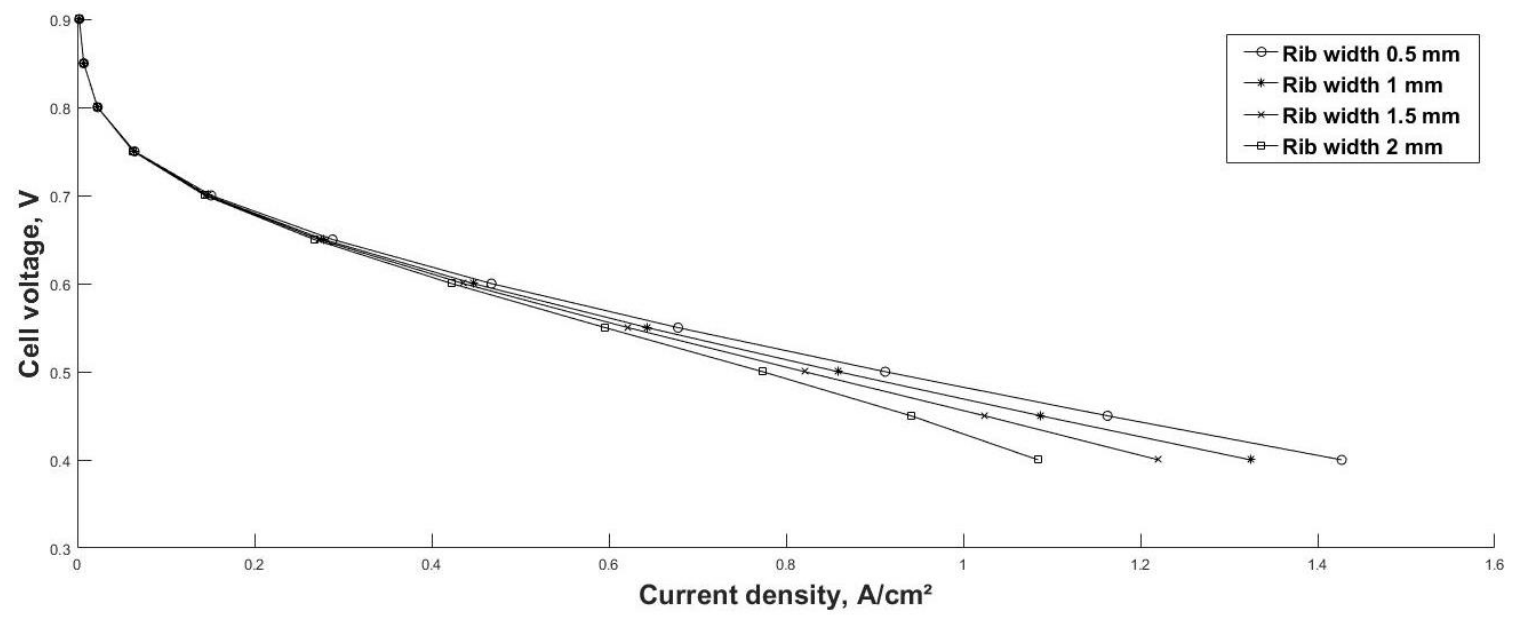

Figure 3. Variation of cell voltage with current density for various rib widths. 
The effect of changing rib width is not seen to play significant role at lower current densities. Also, it seems that the channel width plays a certain role, even at lower current densities

Figure 4 shows the effect of pressure drop for various channel lengths for different rib width values $(0.5,1,1.5,2 \mathrm{~mm})$. The pressure drop is found to increase from $47 \mathrm{kPa}$ when the channel length is $19 \mathrm{~mm}$ to $53 \mathrm{kPa}$ at the channel length of $25 \mathrm{~mm}$ when the rib width is maintained at $0.5 \mathrm{~mm}$. When the rib width is increased to $2 \mathrm{~mm}$, the pressure drop is seen to change from 46.5 to $52 \mathrm{kPa}$ for channel lengths changing from 19 to $25 \mathrm{~mm}$. Goebel [10] postulated that for greater pressure drop across the channel length, the greater is water transport, leading to better removal of water in a PEMFC. This in turn leads to better oxygen consumption leading to better fuel cell performance. The pressure drop across the channel lengths when the rib width is changed from 0.5 to $2.0 \mathrm{~mm}$, enables better water transport and hence better oxygen consumption, thus allowing better PEMFC performance. Smaller ribs also reduce the ohmic drop across the cell, enabling higher current densities.

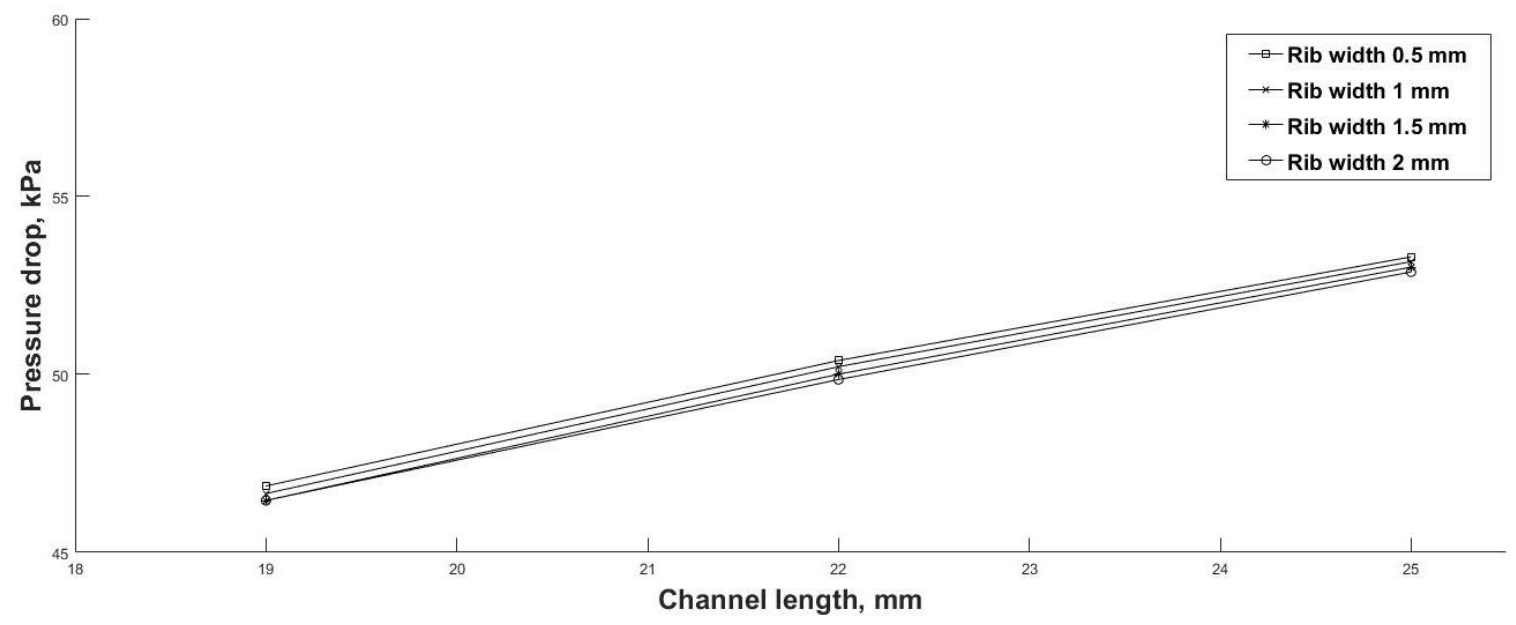

Figure 4. Pressure drop as a function of three different channel lengths $(19 \mathrm{~mm}, 22 \mathrm{~mm}$ and 25 $\mathrm{mm}$ ) for various rib widths.

Figure 5 shows the simulated polarization curves for varying channel widths. The figure shows that increasing values of the channel width plays a certain role in the performance of the fuel cell, particularly at higher current densities. It seems, however, that the channel width plays some role even at lower current densities.

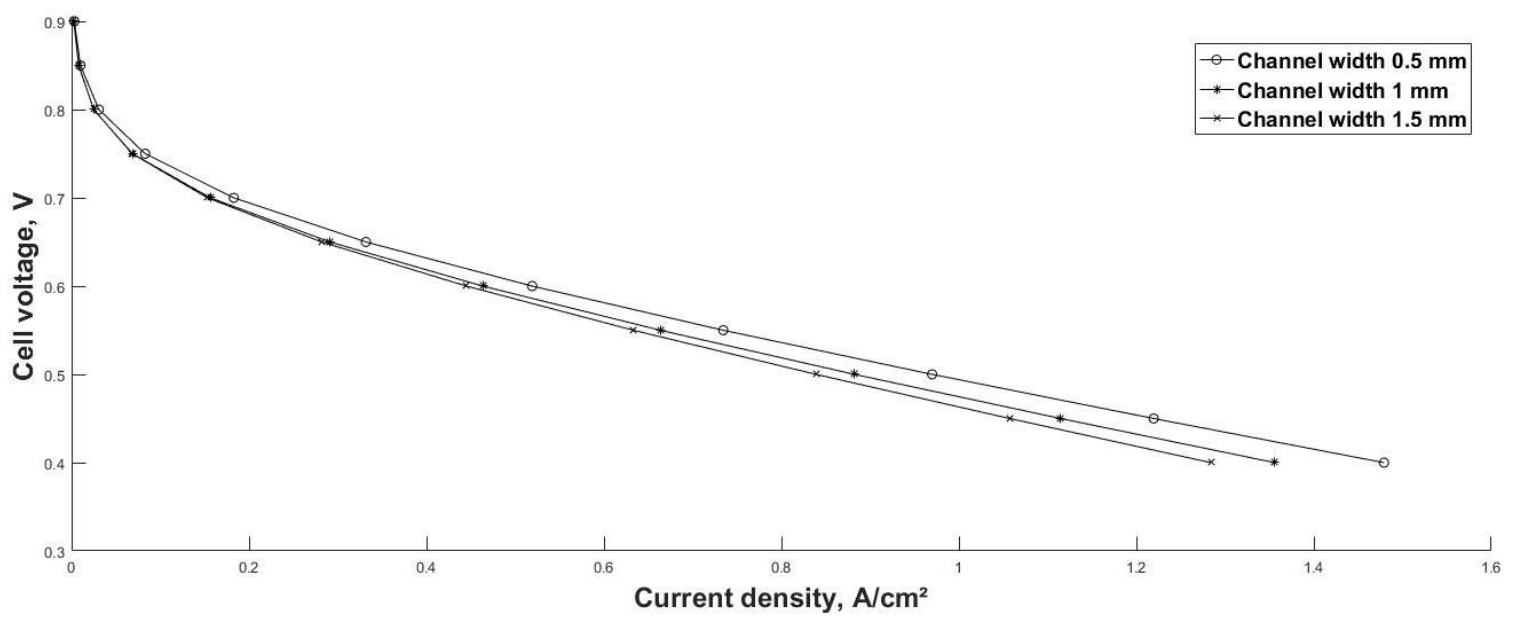

Figure 5. Polarization curves showing the variation of cell voltage with cell current density for various channel widths. 
Figure 6 shows the pressure drop across the length of the channel as a function of changing channel width. The figure shows that the pressure drop changes from $63 \mathrm{kPa}$ at the channel length of $19 \mathrm{~mm}$ to $70 \mathrm{kPa}$ at the channel length of $25 \mathrm{~mm}$ for the channel width of $0.5 \mathrm{~mm}$. At the channel width of $1.5 \mathrm{~mm}$, the pressure drop is found to change from $35 \mathrm{kPa}$ at the channel length of $19 \mathrm{~mm}$ to $42 \mathrm{kPa}$ at the channel length of $25 \mathrm{~mm}$. Thus, there is a significant effect of pressure drop on the water transport in the cathode gas channels, leading to significant fuel cell performance improvement particularly at high current densities. However, a wider gas channel also allows enhanced surface reaction on the cathode side enabling more oxygen consumption. However, the pressure drop seems to be a dominant effect and hence we see better performance when the channel width is $0.5 \mathrm{~mm}$.

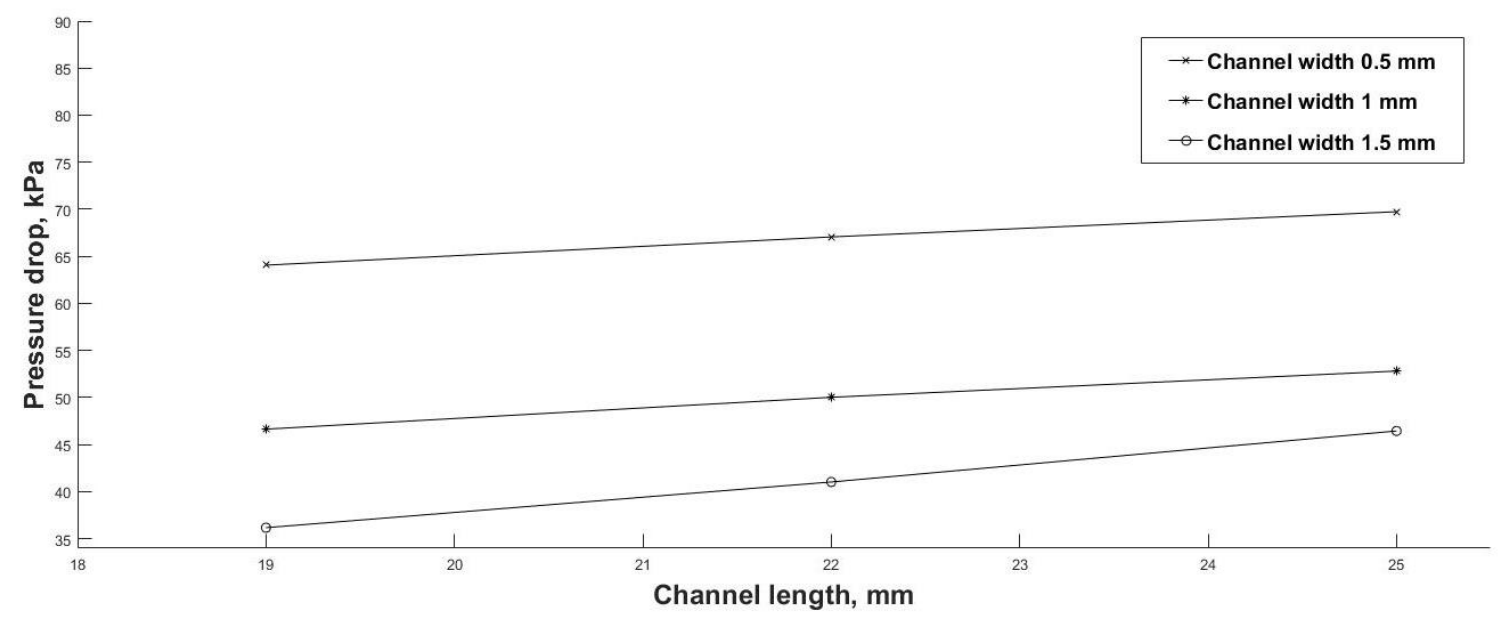

Figure 6. Pressure drop at three different channel length values (19, 22 and $25 \mathrm{~mm}$ ) for different channel widths.

Figure 7 shows the simulated polarization curves for varying rib/channel ratios. The graph shows that if the total channel width and rib width is fixed, with increasing values of the rib width, the fuel cell performance decreases. The highest performance is seen at the lowest value of the rib width. This indicates the effect of the electrical resistance of the rib width and the consequent effect on the ohmic drop in the PEM fuel cell.

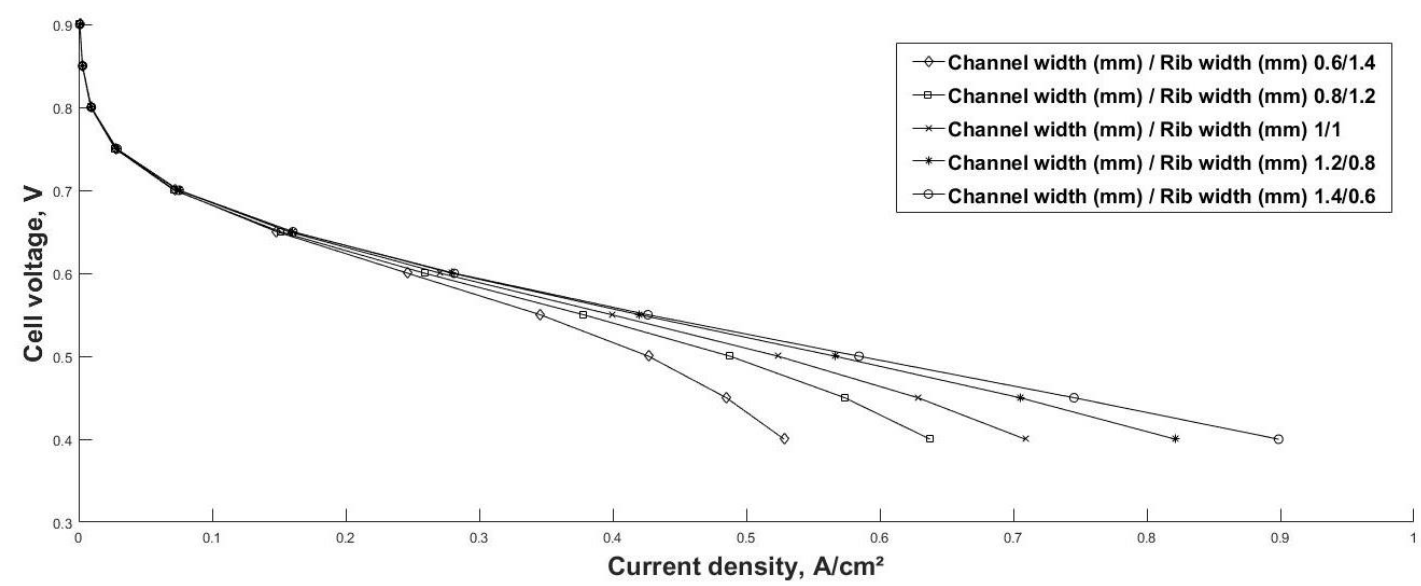

Figure 7. Polarization curves for different channel width to rib ratios (channel width+rib width=2).

Figures $8 \mathrm{a}$ and $8 \mathrm{~b}$ show the effect of change in oxygen concentration across the channel length when the channel width is changed from 0.5 to $1.5 \mathrm{~mm}$. The channel length is this case is fixed at $25 \mathrm{~mm}$. The oxygen consumption is seen to be higher when the channel width is $0.5 \mathrm{~mm}$ than $1.5 \mathrm{~mm}$, clearly showing the effect of pressure drop across the cathode channel length. 


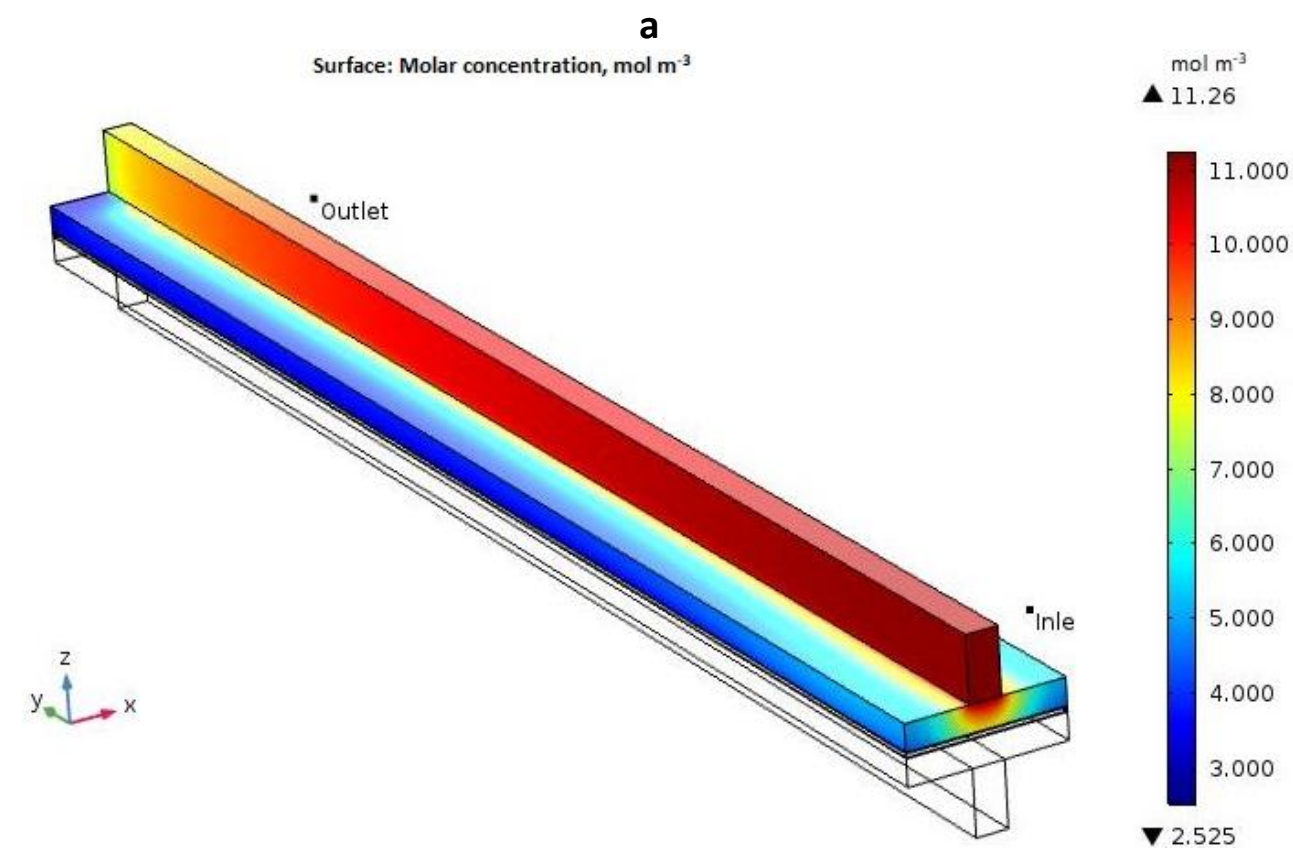

b

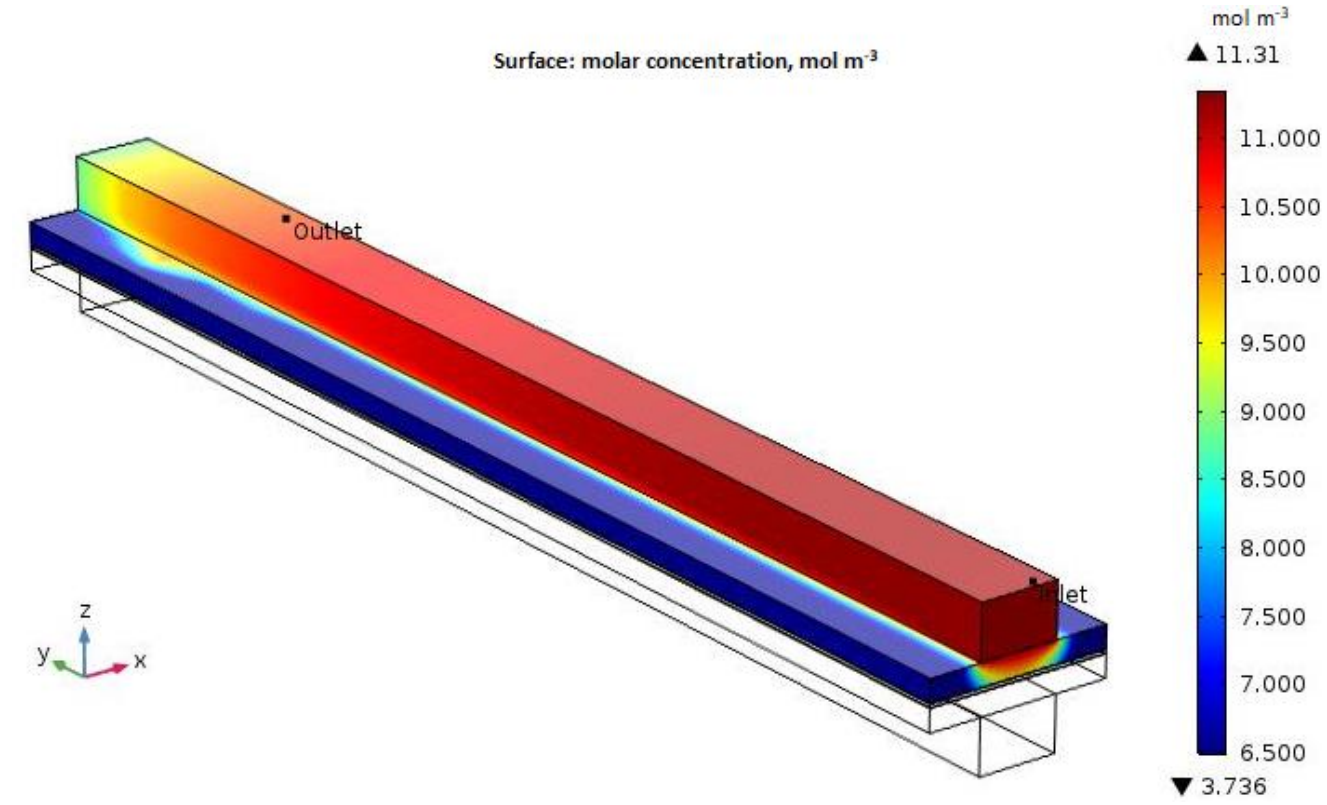

Figure 8. Oxygen concentration profile: (a) along the cathode gas channel when the channel width is 0.5 $\mathrm{mm},(b)$ in the cathode gas channel when the channel width is $1.5 \mathrm{~mm}$.

Figure 9 shows the performance of the high temperature PEMFC as a function of various channel depths. The figure shows that the channel depth plays very little role if any, in the performance of the PEMFC.

Figures $10 \mathrm{a}$ and $10 \mathrm{~b}$ show the oxygen concentration across the flow channel length as a function of two different channel depth values $(0.5$ and $1.5 \mathrm{~mm})$. The channel length in this case is fixed at $25 \mathrm{~mm}$. The figures show that the oxygen consumption is not changed much by changing the channel depth. Figure 11 shows the effect of cathode channel length on the pressure drop in the cathode channel for a given current density (for three different channel widths). The graph indicates that the maximum pressure drop is obtained when the channel length is $25 \mathrm{~mm}$.

Validation of simulation results with experimental data [13] is shown in Figure 12. Simulation results are well compared with experimental data. The parameters used for fitting experimental data are shown in Table 1. 


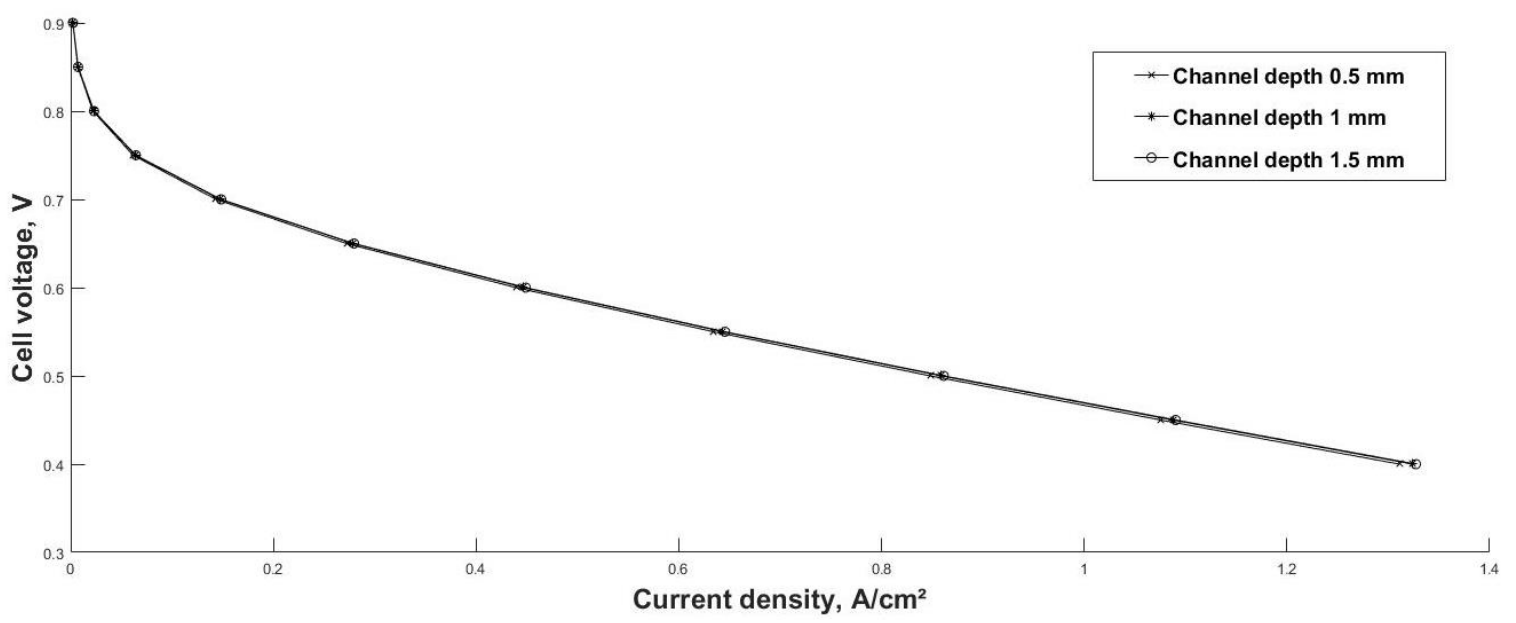

Figure 9. Variation of cell voltage with current density for various cell channel depths.

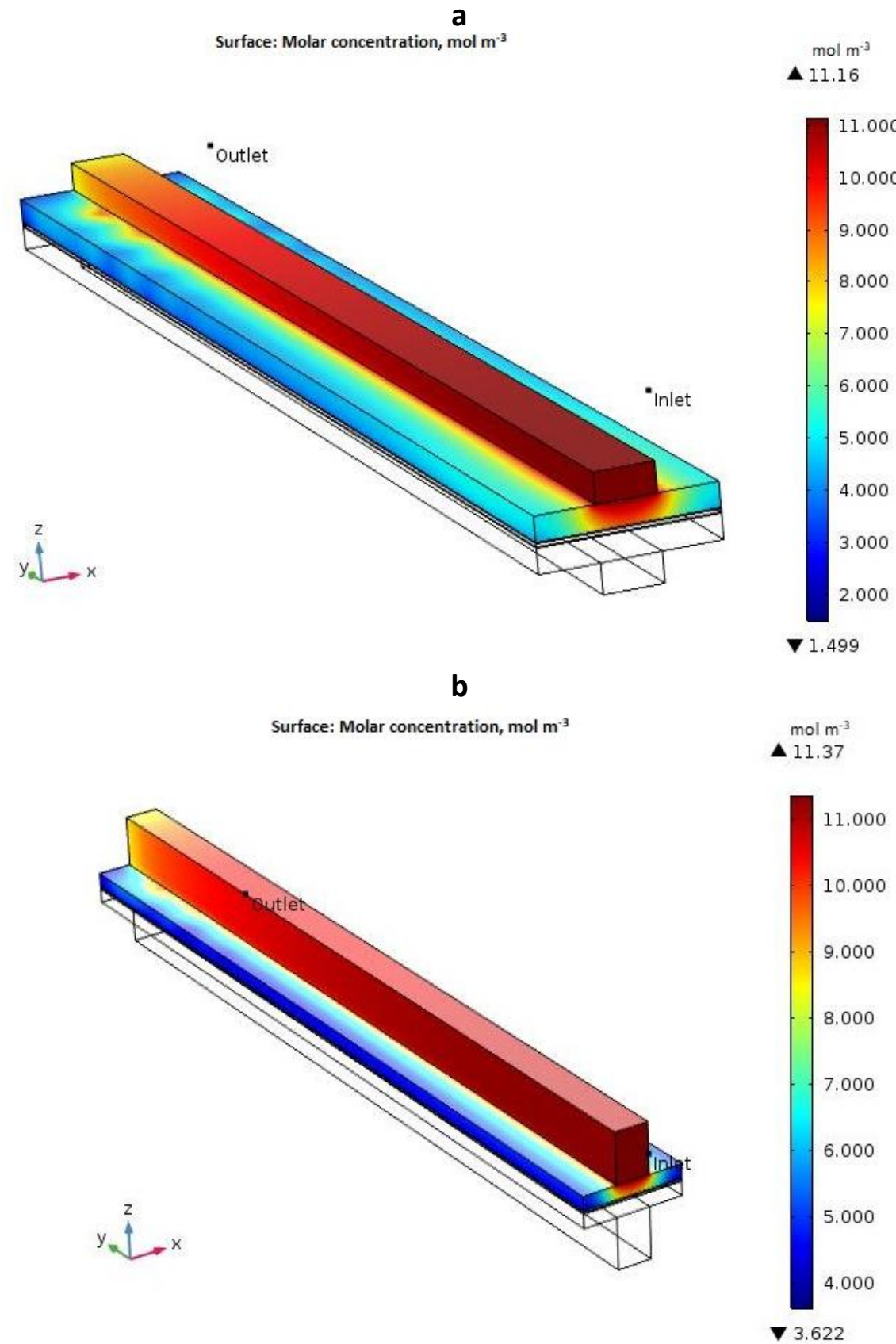

Figure 10. Concentration profile of oxygen: (a) in the cathode gas channel for $0.5 \mathrm{~mm}$ channel depth, (b) in the cathode gas channel for $1.5 \mathrm{~mm}$ channel depth. 


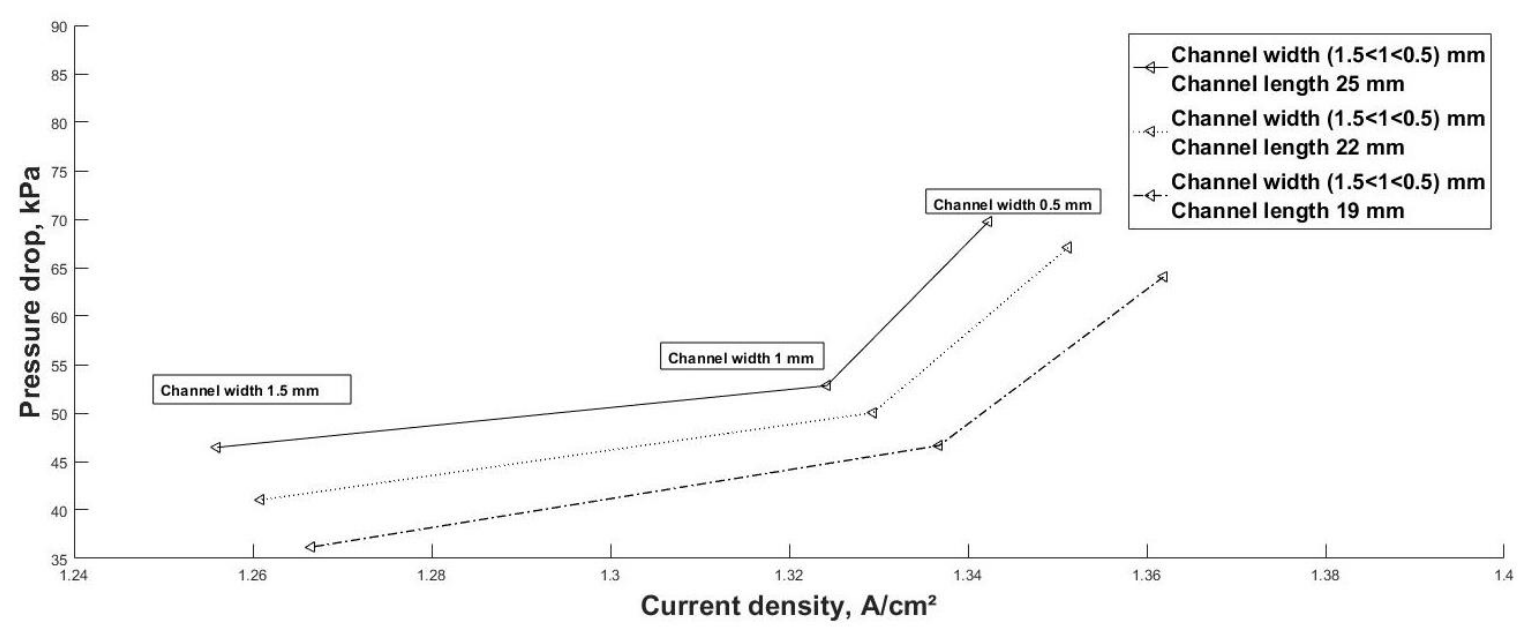

Figure 11. Effect of channel length on current density of the cell for three different channel widths.

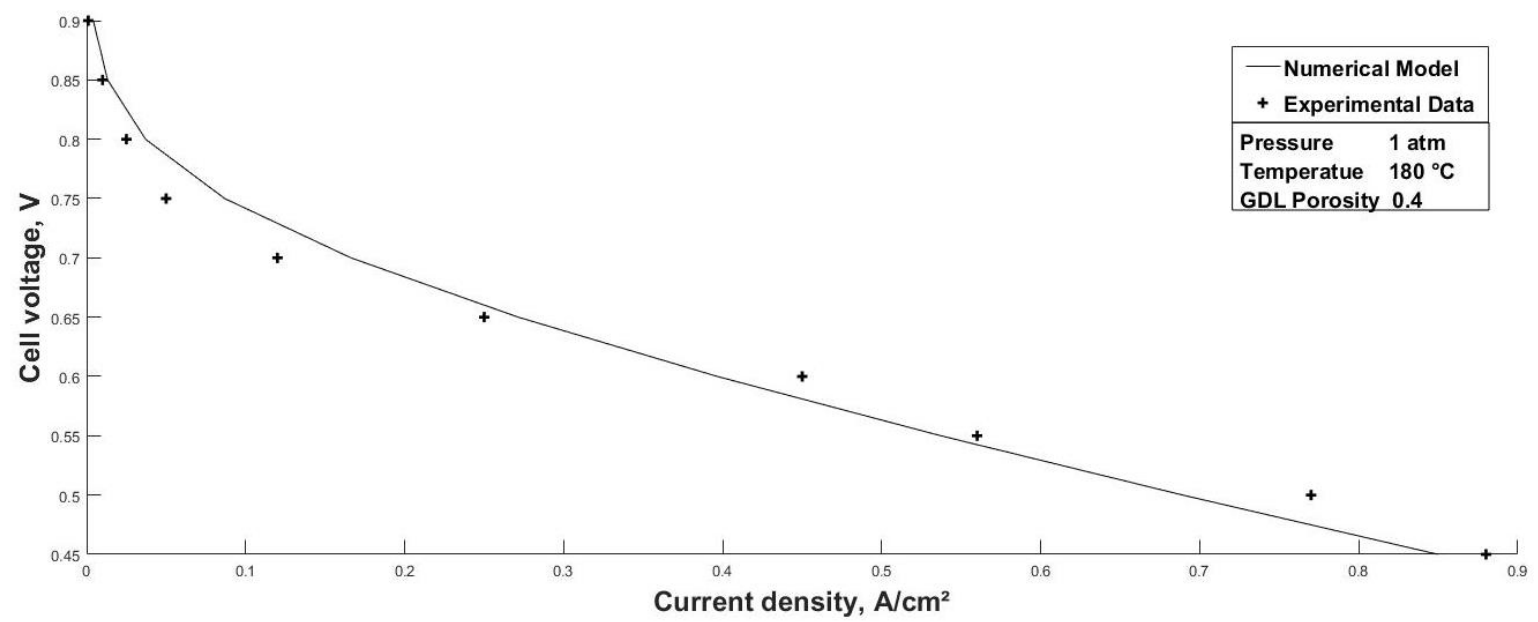

Figure 12. Validation of modeling predictions with experimental data.

Table 1. List of parameters and nomenclature

\begin{tabular}{|c|c|c|}
\hline Notation & Values & Description \\
\hline$x_{0}$ & 0.3 & Inlet oxygen mass fraction (cathode) \\
\hline$x_{\mathrm{H}}$ & 1.00 & Inlet hydrogen mass fraction (anode) \\
\hline$w_{\mathrm{r}}, w_{\mathrm{ch}}, h_{\mathrm{c}} / \mathrm{mm}$ & $0.5,1,1.5$ & Rib width, channel width, channel depth \\
\hline$V_{\text {cell }} / \mathrm{V}$ & 0.4 & Cell voltage \\
\hline$u_{\mathrm{c}} / \mathrm{m} \mathrm{s}^{-1}$ & 0.5 & Cathode inlet flow velocity \\
\hline$u_{\mathrm{a}} / \mathrm{m} \mathrm{s}-1$ & 0.2 & Anode inlet flow velocity \\
\hline$T /{ }^{\circ} \mathrm{C}$ & 130 & Cell temperature \\
\hline$\sigma, \sigma_{\mathrm{s}} / \mathrm{S} \mathrm{m}^{-1}$ & $9.825,222$ & Membrane, GDL conductivity \\
\hline$P_{\mathrm{a}}, p_{\mathrm{c}} / \mathrm{atm}$ & 1 & Reference pressure at anode and cathode \\
\hline$\mu_{\mathrm{c}} / \mathrm{Pa} \mathrm{s}$ & $2.46 \times 10^{-5}$ & Cathode viscosity \\
\hline$\mu_{\mathrm{a}} / \mathrm{Pa} \mathrm{s}$ & $1.19 \times 10^{-5}$ & Anode viscosity \\
\hline$L / \mathrm{mm}$ & $19,22,25$ & Cell length \\
\hline$\kappa / m^{2}$ & $10^{-12}$ & GDL permeability \\
\hline$F / \mathrm{C} \mathrm{mol}^{-1}$ & 96487 & Faraday's constant \\
\hline$R / \mathrm{J} \mathrm{mol}^{-1} \mathrm{~K}^{-1}$ & 8.314 & Universal gas constant \\
\hline$H_{\mathrm{m}}, H_{\mathrm{cl}} / \mathrm{mm}$ & $0.1,0.05$ & Membrane, electrode thickness \\
\hline$\varepsilon$ & 0.3 & Electrolyte phase volume fraction \\
\hline$\varepsilon_{\mathrm{gdl}}$ & 0.4 & GDL porosity \\
\hline$D_{\mathrm{O}, \mathrm{N}} / \mathrm{m}^{2} \mathrm{~s}^{-1}$ & $2.2 \times 10^{-5}(T / 293.2)^{1.75}$ & $\mathrm{O}_{2}-\mathrm{N}_{2}$ binary diffusion coefficient \\
\hline$D_{\mathrm{O}_{2} \mathrm{H}_{2} \mathrm{O}} / \mathrm{m}^{2} \mathrm{~s}^{-1}$ & $2.2 \times 10^{-5}(T / 293.2)^{1.75}$ & $\mathrm{O}_{2}-\mathrm{H}_{2} \mathrm{O}$ binary diffusion coefficient \\
\hline$D_{\mathrm{N}, \mathrm{H}, \mathrm{O}} / \mathrm{m}^{2} \mathrm{~s}^{-1}$ & $2.2 \times 10^{-5}(T / 293.2)^{1.75}$ & $\mathrm{~N}_{2}-\mathrm{H}_{2} \mathrm{O}$ binary diffusion coefficient \\
\hline$D_{\mathrm{H}_{2} \mathrm{H}_{2} \mathrm{O}} / \mathrm{m}^{2} \mathrm{~s}^{-1}$ & $2.2 \times 10^{-5}(T / 293.2)^{1.75}$ & $\mathrm{H}_{2}-\mathrm{H}_{2} \mathrm{O}$ binary diffusion coefficient \\
\hline $\mathrm{C}_{\mathrm{O}}{ }^{\mathrm{ref}} / \mathrm{mol} \mathrm{m}^{-3}$ & 40.88 & Oxygen reference concentration \\
\hline $\mathrm{C}_{\mathrm{H}}{ }^{\text {ref }} / \mathrm{mol} \mathrm{m}^{-3}$ & 40.88 & Hydrogen reference concentration \\
\hline$H_{g d l}, H_{\mathrm{ch}} / \mathrm{mm}$ & $0.38,1$ & GDL depth, channel depth \\
\hline
\end{tabular}




\section{Conclusions}

A three-dimensional numerical model is developed to study the effect of channel and rib dimensions on HT-PEM fuel cell performance in a parallel flow configuration run at $130{ }^{\circ} \mathrm{C}$. Simulation results indicate that changing the rib width (channel width and channel depth are kept constant) has the maximum effect on the fuel cell performance. Changing the channel width (rib width and channel depth are kept constant) has a significant effect while changing the channel depth has negligible effect on the fuel cell performance. The effect of changing rib width, channel width and channel depth on the pressure drop across the channel is also studied. Increasing pressure drop across the channel length facilitates water vapor transport and hence increases oxygen consumption. Model results are found to compare well with experimental data.

Acknowledgement: The authors would like to acknowledge BITS Pilani, Hyderabad and Council for Scientific and Industrial Research, CSIR Grant No: (No:22/0784/19/EMR II) to support us in publishing this article.

\section{References}

[1] Y. G. Yoon, W. Y. Lee, G. G. Park, T. H. Park, T. H. Yang, S. H. Kim, Electrochimica Acta 50(2-3) (2004) 709-712.

[2] S. Shimpalee, J. W. Van Zee, International Journal of Hydrogen Energy 32(7) (2007) 842-856.

[3] S. Shimpalee, S. Greenway, J. W. Van Zee, Journal of Power Sources 160(1) (2006) 398-406.

[4] S. S. Hsieh, K. M. Chu, Journal of Power Sources 173(1) (2007) 222-232.

[5] A. P. Manso, F. F. Marzo, J. Barrancco, X. Garikano, M. Garmendia Mujika, International Journal of Hydrogen Energy 37(20) (2012) 15256-15287.

[6] X. D. Wang, Y. Y. Duan, W. M. Yan, X. F. Peng, Electrochimica Acta 53(16) (2008) 5335-5343.

[7] X. D. Wang, W. M. Yan, Y. Y. Duan, F. B. Weng, G. B. Jung, C. Y. Lee, Energy Conversion and Management 51(5) (2010) 959-968.

[8] M. Z. Chaudhary, O. Genc, S. Toros, International Journal of Hydrogen Energy 43(23) (2018) 1079810809.

[9] L. J. Yu, G. P Ren, M. J. Qin, X. M. Jiang, Renewable Energy 34(3) (2009) 530-543.

[10] S. G. Goebel, Journal of Power Sources 196(18) (2011) 7550-7554.

[11] C. Wang, Q. Zhang, S. Shen, X. Yan, F. Zhu, X. Cheng, J. Zhang, Scientific Reports 7 (2017) 43447. https://doi.org/10.1038/srep43447.

[12] H. Liu, P. Li, K. Wang, International Journal of Hydrogen Energy 38(23) (2013) 9835-9846.

[13] E. U. Ubong, X. Wang, Z. Shi, Journal of the Electrochemical Society 156(10) (2009) B1276-B1282.

(C)2021 by the authors; licensee IAPC, Zagreb, Croatia. This article is an open-access article distributed under the terms and conditions of the Creative Commons Attribution license (https://creativecommons.org/licenses/by/4.0/) 